\title{
short stop Is Allelic to kakapo, and Encodes Rod-Like Cytoskeletal- Associated Proteins Required for Axon Extension
}

\author{
Seungbok Lee, ${ }^{1}$ Kerri-Lee Harris, ${ }^{2}$ Paul M. Whitington, ${ }^{2}$ and Peter A. Kolodziej ${ }^{1}$ \\ ${ }^{1}$ Department of Cell Biology, Center for Molecular Neuroscience and Howard Hughes Medical Institute, Vanderbilt \\ University Medical Center, Nashville, Tennessee 37232-0295, and 2Molecular and Cellular Biology, School of Biological \\ Sciences, University of New England, Armidale, New South Wales, Australia 2351
}

short stop (shot) is required for sensory and motor axons to reach their targets in the Drosophila embryo. Growth cones in shot mutants initiate at the normal times, and they appear normal with respect to overall morphology and their abilities to orient and fasciculate. However, sensory axons are unable to extend beyond a short distance from the cell body, and motor axons are unable to reach target muscles. The shot gene encodes novel actin binding proteins that are related to plakins and dystrophin and expressed in axons during development. The longer isoforms identified are predicted to contain an $\mathrm{N}$-terminal actin binding domain, a long central triple helical coiled-coil domain, and a C-terminal domain that contains two
EF-hand $\mathrm{Ca}^{2+}$ binding motifs and a short stretch of homology to the growth arrest-specific 2 protein. Other isoforms lack all or part of the actin binding domains or are truncated and contain a different C-terminal domain. Only the isoforms containing full-length actin binding domains are detectably expressed in the nervous system. shot is allelic to kakapo, a gene that may function in integrin-mediated adhesion in the wing and embryo. We propose that Shot's interactions with the actin cytoskeleton allow sensory and motor axons to extend.

Key words: Drosophila; cytoskeleton; GAS2; axon; growth cone; short stop; kakapo
The tips of developing axons, growth cones, undergo complex morphological changes in response to extracellular guidance cues (Tessier-Lavigne and Goodman, 1996). Rearrangements of the actin cytoskeleton are required for growth cone motility and guidance (Yamada and Wessells, 1973; Letourneau and Marsh, 1984; Bentley and Toroin-Raymond, 1986). Actin is assembled into filaments at the leading edge, transported away from the membrane by a process termed retrograde flow, and then disassembled (Welch et al., 1997). In culture, retrograde flow rates are inversely proportional to the rate of axon extension (Lin and Forscher, 1995). Although the mechanisms are not well understood, actin dynamics in the growth cone are likely coordinated with the movement of other cellular components such as membrane and microtubules.

Mutations that affect axon extension could interfere with different aspects of actin dynamics. For example, mutations in profilin, an actin binding protein (Pollard and Cooper, 1984; Wills et al., 1999), and Rho family GTPases, regulators of actin assembly (Luo et al., 1994; Hall et al., 1998), affect axon extension in the

\footnotetext{
Received April 29, 1999; revised Nov. 4, 1999; accepted Nov. 12, 1999.

K.L.H. is supported by an Australian Postgraduate Award. Financial support to P.W. was provided by an Australian Research Council Large Grant. S.L. is a Postdoctoral Associate, and P.A.K. is an Assistant Investigator of the Howard Hughes Medical Institute. We acknowledge Vanderbilt Cancer Center support for oligonucleotide facilities, the Howard Hughes Medical Institute Duke Microchemistry facility for DNA sequencing, and the Vanderbilt Cell Imaging Resource's support for confocal microscopy (supported by Grants CA68485 and DK20593). We thank Kim Parker for assistance with this manuscript, Chand Desai for helpful discussions, anonymous reviewers for suggestions that improved this manuscript, and Ahmad Rabi for technical support. We thank Stephen Gregory, Nicholas Brown, Andreas Prokop, Dan Strumpf, and Talila Volk for sharing information before publication and antibodies. We thank Corey Goodman, Robert White, and Seymour Benzer for antibodies.

Correspondence should be addressed to Peter Kolodziej, 823 Light Hall, Vanderbilt University Medical Center, Nashville, TN 37232-0295. E-mail: kolodzp@ctrvax.vanderbilt.edu.

Copyright (c) 2000 Society for Neuroscience $\quad 0270-6474 / 00 / 201096-13 \$ 15.00 / 0$
}

Drosophila embryo, and mutations in unc-115, a novel actin binding protein, alter axon development in Caenorhabditis elegans (Lundquist et al., 1998). Although many actin binding proteins are known, relatively few have been shown to affect neuronal morphogenesis in vivo, presumably because they are required earlier in development.

We show here that short stop (shot), a gene required for sensory and motor axon extension, encodes novel proteins that are predicted to contain actin binding domains and are expressed in axons. shot mutants were originally described as affecting the entry of a subset of motor axons into target muscle fields in the Drosophila embryo (Van Vactor et al., 1993). We demonstrate that strong shot mutants, which also affect sensory axon extension (Kolodziej et al., 1995), disrupt the extension of all motor axons. Dye fills of sensory neurons indicate that the timing of outgrowth initiation and the ability of growth cones to form filopodia or lamellopodia appear normal in shot mutants. Sensory and motor growth cones can still assess some directional cues in shot mutants; they orient and extend properly during early parts of their trajectory but fail to continue advancing.

The shot cDNAs match in part those identified recently for kakapo (kak), which encodes a novel, evolutionarily conserved plakin-like, actin binding protein (Gregory and Brown, 1998; Strumpf and Volk, 1998). kak is required for wing epithelium formation (Prout et al., 1997), epidermal muscle attachment cell differentiation (Strumpf and Volk, 1998), and synapse formation (Prokop et al., 1998), but its role in axon extension has not been described. In shot/kak mutants defective in neuromuscular synapse formation, motor axons reach their target muscles (Prokop et al., 1998).

Plakins, such as plectin, bullous pemphigoid antigen 1 (BPAG1), and envoplakin, are long rod-like proteins that bind actin filaments via an $\mathrm{N}$-terminal domain and other cytoskeletal 
proteins or membrane proteins via their C-terminal domain or at other sites (Ruhrberg and Watt, 1997). The long isoforms of Shot/Kak (5500 amino acids) and their mammalian homologs contain a C-terminal domain with homology to the mammalian growth arrest-specific 2 (Gas2) protein, a cytoskeletal-associated protein that is induced in fibroblasts during serum starvation (Schneider et al., 1988). We have identified isoforms that likely differ in their actin binding properties, the length of the rod domain, and the C-terminal domain. Shot thus forms a family of rods predicted to vary between 75 and $220 \mathrm{~nm}$ in length and could play a key role in organizing the cytoskeleton in the $\sim 500-\mathrm{nm}$ wide fly axon.

\section{MATERIALS AND METHODS}

Drosophila strains and genetics. The diepoxybutane-generated short stop alleles used in this study were isolated previously (Kolodziej et al., 1995) and generated on an Oregon R background. The P-element alleles were identified by screening a collection of P-element lethals (Torok et al., 1993) for failure to complement the lethal shot ${ }^{3}$ mutation. Pairwise crosses among all shot alleles confirm that they are part of a single complementation group. The $k a k^{1}$ strain and the deficiency $D f(2 R) C X 1$ were obtained from the Bloomington Stock Center, and the deficiency strains $D f(2 R) S u(z) 2-1 . a 3$ and $D f(2 R) S u(z) 2-1 . a 4$ were a kind gift of Ting Wu (Harvard Medical School). The shot alleles also fail to complement $D f(2 R) C X 1$ and $D f(2 R) \operatorname{Su}(z) 2-1 . a 4$, but complement $\operatorname{Df}(2 R) \operatorname{Su}(z) 2-1 . a 3$. These deficiencies remove the following chromosomal regions: 49D1;50D13, 49D1-E1;50C10, and 49E1-F2; 50B1-C4. Thus, the complementation behavior of shot alleles is consistent with the chromosomal location for shot: 50C6-10 on chromosome II. shot was physically mapped by hybridizing shot cDNA probes to a P1 phage physical array of the fly genome (Genome Systems; Berkeley Drosophila Genome Project) and by identifying the insertion site for $l(2) k 06601$, a P-element allele of shot, on polytene chromosomes (Berkeley Drosophila Genome Project). We reverted the lethality of $l(2) k 05460$ and $l(2) k 06601$ by mobilization of the P-element (Robertson et al., 1988), thus confirming that the lethality of these P-element alleles is attributable to the $\mathrm{P}$-element insertions. To show that the P-elements of $l(2) k 05460$ (shot ${ }^{\mathrm{P} 1}$ ) and $l(2) k 06601\left(s h o t^{\mathrm{P} 2}\right)$ are inserted in shot, the elements were mobilized by crossing in the $\Delta 2-3$ transposase (Robertson et al., 1988). The chromosomes containing excision events were then tested for their ability to complement $s h t^{3}$. Viable excisions were recovered for all P-element shot alleles. Wild-type dye fills were performed on $y w^{\text {Harvard }}$ flies; flies heterozygous for shot mutations were used as wild type in other experiments.

Cloning of shot. Genomic DNA fragments adjacent to the P-elements of $l(2) k 06601$ were isolated by plasmid rescue using EcoRI or SacII and then used as a probe to screen a $\lambda$ gt10 cDNA library (Clontech, Palo Alto, CA) prepared from 12-24 hr embryonic RNA. Seven cDNA clones were isolated and sequenced on both strands. They contain common 3' but one of four different $5^{\prime}$ sequences. Because these partial cDNAs contained long open reading frames without a stop codon, probes derived from the common sequences were used to rescreen both the $\lambda \mathrm{gt} 10$ and a plasmid cDNA library prepared from 12-24 hr embryonic RNA (Brown and Kafatos, 1988). To screen the plasmid library, 50 pools of $\sim 5 \times 10^{4}$ clones were screened by PCR and then screened by filter hybridization to isolate clones containing the $3^{\prime}$ end of shot.

Sequencing was performed using the Perkin-Elmer fluorescent sequencing kit (Perkin-Elmer, Norwalk, CT). The samples were analyzed by the Duke University Microchemistry Facility using an ABI automated sequencer, and the results were edited and compiled using EditView (Perkin-Elmer), AssemblyLign (Oxford Biomolecular), and MacVector (Oxford Biomolecular) software. The predicted amino acid sequences were analyzed using MacVector (Oxford Biomolecular) and MacStripe, a coiled-coil prediction program (Lupas, 1997), and compared with nonredundant sequences using Blastp (Altschul et al., 1990).

Immunohistochemistry. Immunohistochemistry with monoclonal antibodies (mAbs) 1D4 (Van Vactor et al., 1993), 22C10 (Fujita et al., 1982), and 49C4 (Kolodziej et al., 1995) has been described. Whole-mount staining of embryos with antibody against Kak/Shot has been described previously (Kolodziej et al., 1995); fixation in B5 fix $\left(3 \% \mathrm{HgCl}_{2}, 0.12 \%\right.$ $\mathrm{NaOAc}, 5 \%$ formaldehyde $1: 1$ with heptane) for $20 \mathrm{~min}$ followed by devitellinization in $\mathrm{MeOH}$ and rehydration in $\mathrm{PBS} / 0.1 \%$ Triton/0.2\%
BSA improved the sensitivity of the antiserum but did not alter observed pattern of expression. Embryos were staged according to previously described morphological criteria (Campos-Ortega and Hartenstein, 1985). Stage 14 and early stage 15 embryos chosen for dye filling were classified according to the degree of dorsal closure and gut morphology of intact embryos. Antibody-stained embryos were filleted and mounted in $90 \%$ glycerol for photography; homozygous mutant embryos were identified by the absence of $\beta$-galactosidase expression associated with a lacZ-containing $\mathrm{CyO}$ second chromosome balancer. In situ hybridization experiments were performed with shot antisense or sense probes as described (Tautz and Pfeifle, 1989), and the embryos were mounted in Permount (Fisher Scientific, Pittsburgh, PA). In-focus regions were assembled into a photomontage using Adobe Photoshop. Dye injections into lateral chordotonal neurons were performed as described (Merritt and Whitington, 1995) and mounted whole in $70 \%$ glycerol for photography. In-focus regions of digitally recorded optical sections were then photomontaged.

\section{RESULTS}

\section{short stop is allelic to kakapo}

Mutations in short stop (shot) have variable effects on the outgrowth of sensory axons, with shot ${ }^{1}$ being the weakest and $s h o t^{3}$ the strongest allele (Kolodziej et al., 1995). shot ${ }^{1}$ also affects the outgrowth of a subset of motor axons (Van Vactor et al., 1993); the effects of other shot alleles on motor axon outgrowth have not been characterized. To isolate additional shot alleles and to clone the gene, we screened a collection of transposable P-elementinduced lethals (Torok et al., 1993) for failure to complement $s t^{3}$. We identified four lethal P-element insertion alleles: $l(2) k 03010, l(2) k 03405, l(2) k 05460$, and $l(2) k 06601$. We isolated genomic DNA fragments flanking the P-elements by plasmid rescue (Bier et al., 1989) and found that all of the P-elements are inserted within a $15 \mathrm{~kb}$ genomic region based on Southern and sequence analysis (Fig. $1 A$ ). We confirmed that these P-elements are insertions in the shot gene by mobilizing the P-elements and reverting the lethal phenotypes (Robertson et al., 1988) and physically mapping them to the chromosomal region defined genetically to contain shot (see Materials and Methods). Therefore, we renamed $l(2) k 05460$ and $l(2) k 06601$ alleles as shot ${ }^{\mathrm{P} 1}$ and shot ${ }^{\mathrm{P} 2}$, respectively. As described below, embryos homozygous for any of the P-element insertions also lack detectable Shot protein.

Shortly after we completed the shot sequence, we found that it matched partial sequences of kakapo(kak) deposited in the GenBank database (accession numbers AJ011924 and AJ011925). We then tested whether kak (Prout et al., 1997) was allelic to shot and found that the $k a k^{1}$ allele failed to complement chemically generated and P-element shot alleles. The P-element insertions $l(2) k 03010$ and $l(2) k 03405$ were also recently identified as alleles of $k a k$ and renamed as $k a k^{\mathrm{P} 1}$ and $k a k^{\mathrm{P} 2}$, respectively. kakapo, also identified as kopopu (Walsh and Brown, 1998), has been identified as a gene required for adhesion of the wing epithelium (Prout et al., 1997; Walsh and Brown, 1998) and more recently as required for muscle attachment to the epidermis (Gregory and Brown, 1998; Strumpf and Volk, 1998) and neuromuscular synapse formation (Prokop et al., 1998).

\section{The shot/kakapo gene encodes novel proteins that differ in their predicted actin binding properties and are related to plakins and dystrophin}

We used genomic DNA flanking the $\operatorname{shot}^{\mathrm{P} 2}$ insertion to identify shot gene transcripts. We screened a $\lambda \mathrm{gt} 10$ cDNA library with adjacent DNA fragments, and 15 different overlapping clones were recovered and partially sequenced. These cDNAs all encode predicted proteins with homology to the plakin and dystrophin 

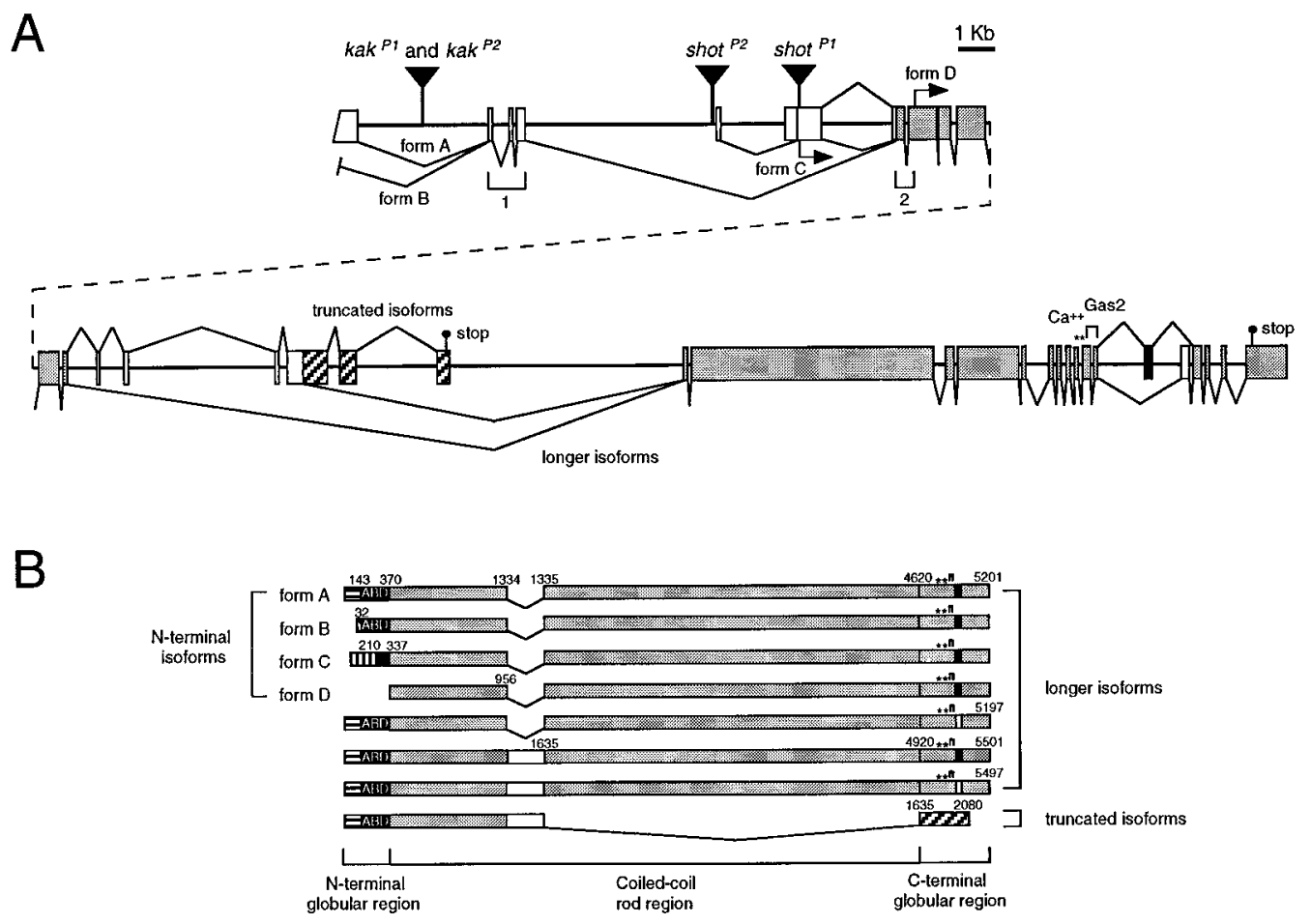

Figure 1. Multiple transcriptional starts and alternative splicing throughout the short stop/kakapo gene generate protein isoforms predicted to differ in their actin binding properties (isoform types $\mathrm{A}-\mathrm{D}$ ), rod domain length, and $\mathrm{C}$-terminal domains. A, The genomic structure of the shot/kak gene at 50C6-10 on chromosome II and P-element insertion sites. Inverted triangles indicate the sites of P-element insertions, and the arrows in the 5' end of the gene indicate the likely transcription start points for the mRNAs encoding isoforms $\mathrm{C}$ and $\mathrm{D}$, as inferred from the corresponding cDNAs. The boxes represent exons (35) mapped in the shot gene by comparison of cDNA with genomic DNA sequence (Berkeley Drosophila Genome Project), and the patterns of alternative splicing are indicated. The first exon shown is exon 3. An additional two exons that encode the $5^{\prime}$ ends of isoforms A and B, respectively, are located upstream of this genomic region (Gregory and Brown, 1998), and their sizes and positions have not been analyzed in this study. Gray boxes indicate exons common to longer isoforms; white boxes indicate alternatively spliced exons. Black box indicates an alternatively spliced exon in the sequence encoding the long isoform $\mathrm{C}$-terminal domain; cross-hatched boxes indicate the exons encoding the $\mathrm{C}$-terminal domain of the shorter isoform. The exons indicated by brackets 1 and 2 encode the predicted actin binding domain found in isoforms $\mathrm{A}$ and $\mathrm{B}$; the exons indicated by bracket 2 are the only portion of the predicted actin binding sequences retained in the isoform $\mathrm{C}$ mRNA. Asterisks denote the exons encoding the $\mathrm{Ca}^{2+}{ }_{\text {-binding }}$ EF-hand motifs (Ikura, 1996). The exons encoding the GAS2 domain are indicated. $B$, Some of the predicted proteins encoded by the shot gene. Four different N-terminal sequences were identified. Two isoforms (A and B) contain complete predicted actin binding domains (black box labeled $A B D$ ), following unique sequences of 143 (horizontal striped box) or 32 amino acids (cross-hatched box), respectively. Isoform C contains a partial ABD (black box), following a unique sequence of 210 amino acids (vertically striped box), and isoform D contains no globular N-terminal domain. Alternative splicing in the middle of the protein can cause the insertion of a 300 amino acid coiled-coil sequence (long white box), and alternative splicing of the C-terminal domain of the long isoform generates additional diversity (small black or white boxes). The rod domain is shaded in gray. A second C-terminal domain (long cross-hatched box) is associated with a shorter rod domain. The numbers refer to the amino acid residues at the junction of these different protein domains for each isoform depicted. Some of the combinatorial possibilities are diagrammed for variants of isoform A; the other N-terminal sequences may exist in similar combinations.

families of actin binding proteins (Michalak and Opas, 1997; Ruhrberg and Watt, 1997). These rod-like proteins link actin to other cytoskeletal or membrane proteins. Complete sequencing of seven of these cDNAs revealed four classes (A, B, C, and D) of alternatively initiated or spliced transcripts (Figs. 1, 2A). Interestingly, the predicted proteins encoded by these cDNAs differ in the extent of the actin binding domain that they retain, as well as in their extreme N-terminal sequences (Fig. $2 A$ ).

Four cDNAs contained sequences encoding isoforms $\mathrm{A}$ and $\mathrm{B}$ of Kak (Gregory and Brown, 1998). Isoform A contains a unique 143 amino acid $\mathrm{N}$-terminal sequence; isoform B contains a unique 32 amino acid $\mathrm{N}$-terminal sequence. The $\mathrm{N}$-terminal sequences in isoforms $\mathrm{A}$ and $\mathrm{B}$ are followed by a 227 amino acid domain that is predicted to bind actin (Fig. $2 A$ ). This actin binding domain contains the region of highest homology ( $60 \%$ sequence identity, $88 \%$ sequence similarity) to plakins such as plectin, ACF7, and BPAG1 (Fig. 2B). The corresponding domains of BPAG1 (Yang et al., 1996) and plectin (Andra et al., 1998) have been shown to bind actin in vitro and in vivo.
Two shot cDNAs (form C) encode a third unique N-terminal sequence of 210 amino acids followed by half of the actin binding domain (Figs. 1, 2A). This second half of the actin binding domain is less evolutionarily conserved (40\% identical with the plakins shown here) than the first half of the actin binding domain (81\% identical with these other plakins) (Fig. 2B). The mammalian BPAG1n3 protein also contains a similar half actin binding domain and associates poorly with the actin cytoskeleton in cultured cells (Yang et al., 1999).

Finally, isoform D lacks an identifiable actin binding domain and contains no N-terminal globular domain (Figs. 1, 2A). The likely initiator methionine codon for isoform $\mathrm{D}$ is located downstream of sequences encoding the actin binding domain, at the start of sequences encoding the central rod domain (Fig. 1A).

Thus, shot encodes various rod-like proteins predicted to differ in their actin binding properties. The genes for other plakins (Ruhrberg and Watt, 1997) also encode similarly spliced actin binding variants (Fig. 2B). Four different 5 ' isoforms are encoded by the BPAG1 gene (Brown et al., 1995a,b; Yang et al., 1999). 
A

form A M TSHSYYKDRIGFDPNEQQPGSNNSMKRSSSRQTTHHHQSYHHATTSS SQ 50 SPARISVSPGGNNGTLEYQQVQREQRDRELYSNNGSLHHHQHHHHHHRHS 100 TTGSASSPLYENSSSPAAPKKAKHSSTQAQPOGGYEDALTQFKDERTAIQ 150

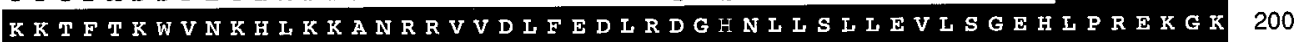

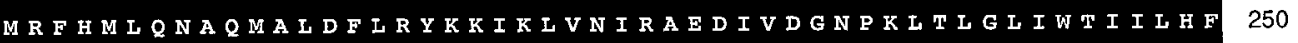
QISDIVVGKEDNVSAREAIIRWARRSTARYPGVRVNDFTS SWRDGLAFSA 300 L V F R R P L L D W KARNDRPRERLETAFHIVEKGYGVTRLIDPEDVDTNE 350

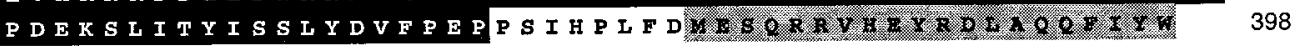

form B MMDRESLSEWAKDKPLSILQLDPADRAVLRIADERDAIQKKTFTKWVNKH LKKANRRVVDLFEDLRDG FNLLSLLEVLSGEHLPREKGKMRFHMLQNAQM 100

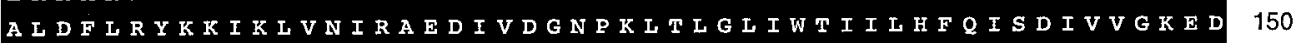
NVSAREALLRWARRSTARYPGVRVNDFTSSWRDGLAFSALVHR R P DLD 200 WRKARNDRPRERIETAFHIVEKEYGVTRLLDPEDVDTNEPDEKSITTYIS 250

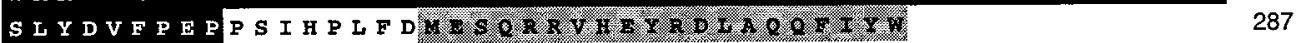

form C MHSSSQSTLKRTQQLVRQTNGGRGDVLSSGSEVVHSSRGPATTTNIDDSN 50 LRYRHETKRERTVEAVITDYPGVSPLGSVPHERTNFERTVTFQDPTGNSR 100 RISETGALVPAGAIPTSSTHYQQVTRNKRISTEVLGSSVESTKTSQRAPN 150 GHRRVTTHIVRKVTTLSRAEENAQPAEDLIPPAKMIRSSELEYRRALPPA 200 IESSSTQRREISDIVVGKEDNVSAREALIRWARRSTARYPGVRVNDFTSS 250 WR DGLAFSALVHRNRPDLLDWRKARNDRPRERLETAFHIVBKEYGVTRLI 300

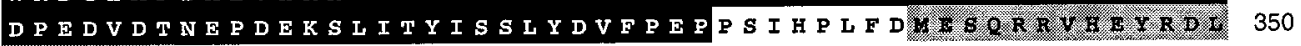
1. $0.9 .+2.1 \%$

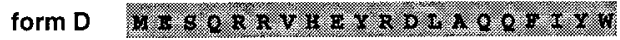

\section{B}

dShot/dKak mACF7

hPlectin hBPAG1

dShot/dKak

mACF7

hPlectin

hBPAG1

dShot/dKak

mACF7

hPlectin

hBPAG1

dShot/dKak

mACF7

hPlectin

hBPAG1

dShot/dKak

mACF7

hPlectin

hBPAG1

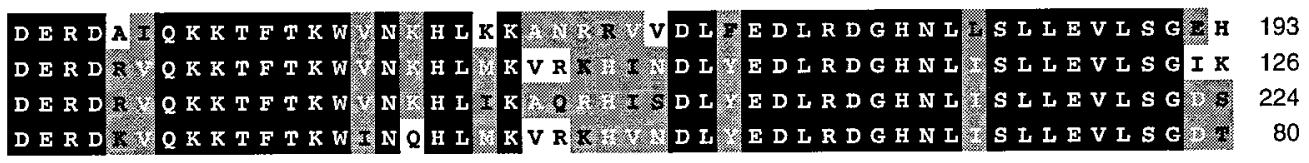

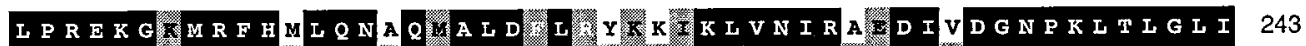

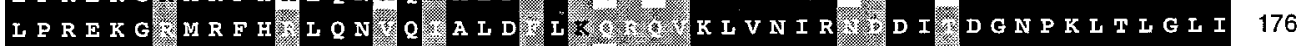

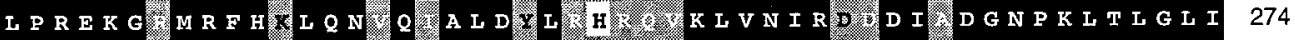
L PREKG MR F H L $Q N$ W

$\nabla$

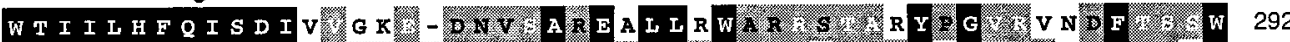

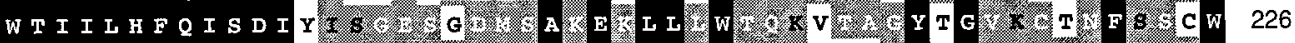
W T I I I F F I S D I Q

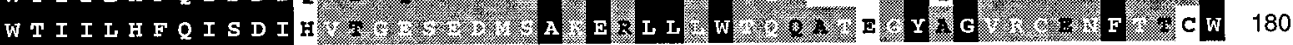
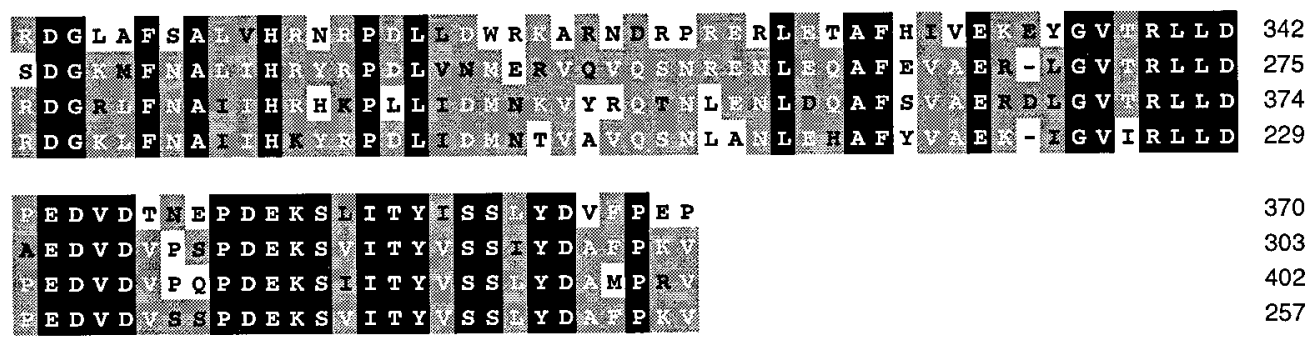

370

303

402

257

Figure 2. The shot gene encodes isoforms predicted to vary in their actin binding properties. $A$, The four predicted N-terminal amino acid sequences of Shot/Kak isoforms. The sequence shaded in black encodes the predicted actin binding domain in different isoforms. Only half of this sequence is present in isoform C (accession number AF200422), and isoform D (accession number AF200423) contains no actin binding sequences. The sequences shaded in gray indicate the sequences common to all isoforms. $B$, Comparison of the predicted actin binding domain sequence from Drosophila Shot isoform A (dShot; accession number CAA09869) with the corresponding sequences in mouse ACF7 (mACF7; accession number AAC52989), human plectin (hPlectin; accession number CAA91196), and human BPAG1 (hBPAG; accession number I39160). BPAG1 is also known as dystonin. Sequence identities are indicated by white letters, with identities among all four sequences indicated on a black background. Sequence similarities ( +1 or more in a PAM 250 matrix) are indicated by black letters on a gray background. The inverted triangle marks where the second half of the actin binding domain begins, as found in Shot isoform C, hBPAG1n3 (accession number AAD49334) (Yang et al., 1999), and mACF isoform 3 (accession number AAC52990) (Bernier et al., 1996). 
QLGERMRSCETAIGLMKNLOSSVQVEESWVDGTTERLSAMPTATSAYEID

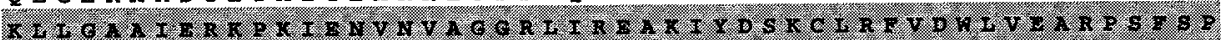

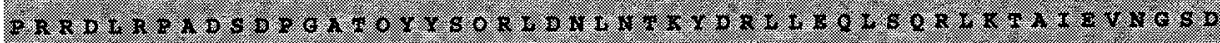

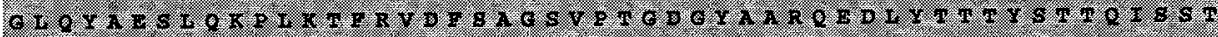

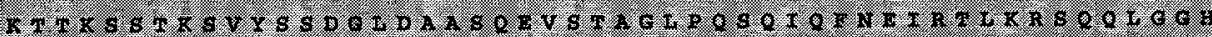

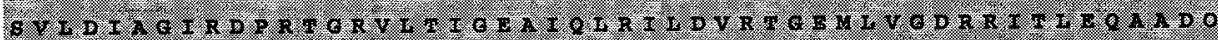

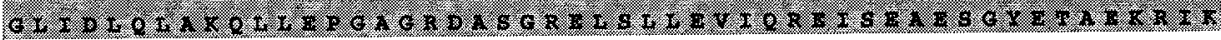
VNATVTVEQTSGELGSPENPRNIADAITAGSVDTKTGLYRVKSGOTISLA EAYERGYLIRHESVTIKSNALCLSDAIAHGLVDGAGWIADRNSGDKFRLD SAIANOLIDASVREVVDAKRDTKITLQEALQSGVLNAKTGRYVNEVTKEK LTFAEARNRQLIVKPYTLKDICDINILDKQAQITSPMRREKLSIMQAIEA GVLDGNIIKCITKRKGELVTLQEAIADGIVIPAECKYRTFMTGEIISIPE AVROGFIDEERQIFKDPKTGNIYSVQQALNYGILVPDSNQTVPEPTNRKK TKSTITIVTKQIIPEAEPIKINTQHTKYVEKSVEIPISQELVKPHRVVSE FINLEKSSYIEQNVTERQIMELPPGGWRLKDAIEQRIFNPDTGVFHVQGT DRLVNFEECINKHSDHNNSNNNYCIKYNNGDRKSGASCVRRCFDHS

B

EF-hand

dKak
dShot
mACF7
KIAA0465
KIAA0728

dKak

dShot

mACF7

KIAA0465

KIAA0728

\section{dKak \\ dShot \\ mACF7 \\ KIAA0465 \\ KIAA0728}

\section{dKak \\ dShot \\ MACF7 \\ KIAA0465 \\ KIAA0728}

$$
\begin{array}{r}
\text { dKak } \\
\text { dShot } \\
\text { mACF7 } \\
\text { KIAA0465 } \\
\text { KIAA0728 }
\end{array}
$$

3765

5111

5018

1394 723 EF-hand

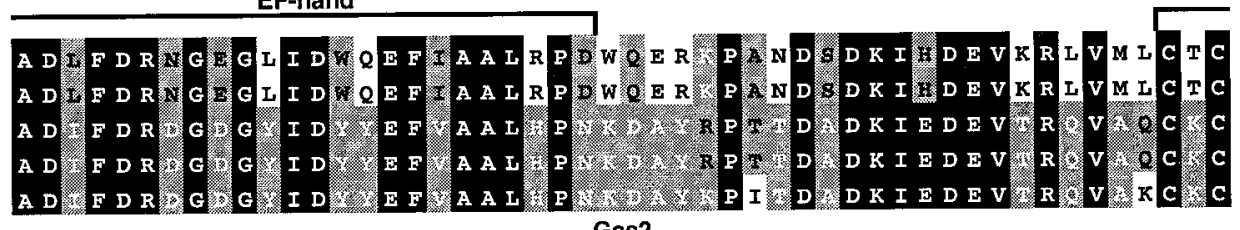

Gas2

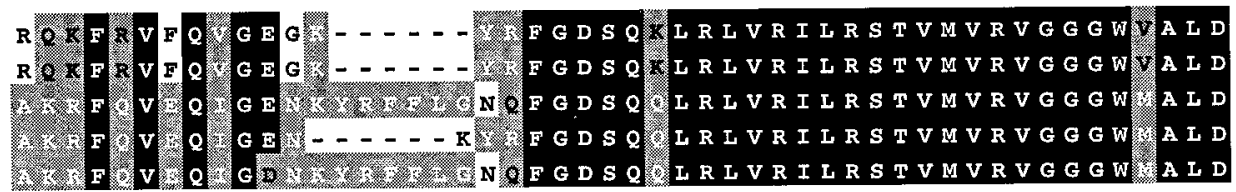
Alternative Splice

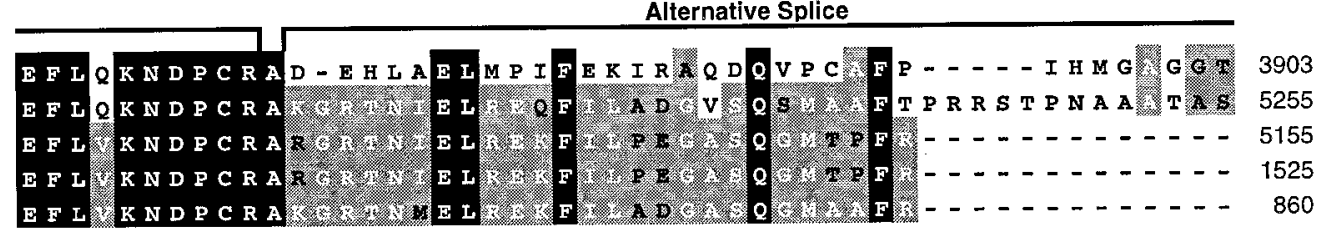
Alternative Splice

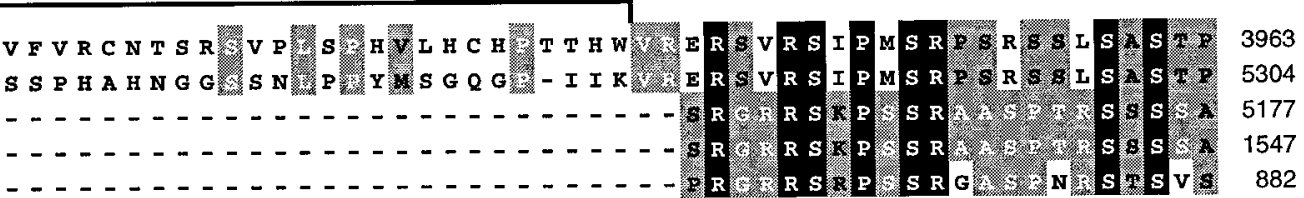

Figure 3. Shot proteins contain different C-terminal domains attached to rodlike domains of varying lengths. $A$, Two classes of long isoforms of Shot/Kak exist, one of which (Gregory and Brown, 1998) contains a 300 amino acid sequence insertion (shaded residues) predicted to form additional coiled-coil sequence. The Shot/Kak isoforms predicted by most of our cDNAs and reported by Strumpf and Volk (1998) lack this sequence. A novel truncated isoform of Shot/Kak is shown here that contains this 300 amino acid insertion, but its rod region terminates in an alternative sequence of 346 amino acids that may form a globular domain (sequence after shaded residues) (accession number AF200424). B, The C-terminal domain of the long isoform of Shot contains two EF-hand motifs and a GAS2 homology domain (Strumpf and Volk, 1998), features that are conserved in the C-terminal domain of novel plakin-like vertebrate proteins. These sequences in Shot/Kak are aligned with the corresponding sequences in ACF7 (accession number AAD32244) and available partial sequences of two plakin-like human proteins (KIAA0465, accession number BAA32310; KIAA0728, accession number BAA34448) (Seki et al., 1997). The accession number for the Kak C-terminal sequence is CAA70581, and the accession number for the Shot C-terminal sequence is AF200425. The sequences of the fly and vertebrate proteins are approximately 200 residues longer than shown and contain additional regions of lower homology. Identical residues are indicated in white, and similar residues are indicated in black. (Figure legend continues) 
Two neuronal isoforms, BPAG1n1 (dystonin-1) and BPAG1n2 (dystonin-2), contain an actin binding domain, a third neuronal isoform, BPAG1n3, contains a half-actin binding domain analogous to that found in Shot isoform $\mathrm{C}$, and the epidermal isoform BPAG1e contains no actin binding domain, as in Shot isoform D. Mouse ACF7 is $71 \%$ identical to BPAG1 within the predicted actin binding domain and encodes $\mathrm{N}$-terminal isoforms similar to Shot isoforms A, B, and C (Bernier et al., 1996). Both isoforms 1 and 2 of mACF7 are predicted to contain a complete actin binding domain; mACF7 isoform 3 lacks the most conserved portion of the actin binding domain and contains the less conserved portion exactly as in Shot isoform C (Fig. 2B) (Bernier et al., 1996).

Our results, in conjunction with those reported previously (Gregory and Brown, 1998), suggest that the shot gene may contain as many as four different promoters (Fig. $1 A$ ). We investigated the relationship between the P-element insertions in shot and the shot promoter and transcription start sites. We used a combination of PCR, Southern analysis, and sequencing to map the shot $^{\mathrm{P} 1}$, shot $^{\mathrm{P} 2}, k_{a k}{ }^{\mathrm{P} 1}$, and $k a k^{\mathrm{P} 2}$ insertion sites and the cDNA sequences onto a $15 \mathrm{~kb}$ genomic DNA contig (Fig. 1A). The $k a k^{\mathrm{P} 1}$ and $k a k^{\mathrm{P} 2} \mathrm{P}$-elements are inserted at the same site, in an intron 1917 bp before the first exon common to mRNAs encoding isoforms $\mathrm{A}$ and $\mathrm{B}$ (Gregory and Brown, 1998) (Fig. 1A). The shot ${ }^{\mathrm{P} 2}$ insertion is 49 bp upstream of the start of alternative transcript $\mathrm{C}$ (Fig. $1 A$ ). The shot $^{\mathrm{P} 1}$ insertion is located in an exon common to both isoforms $\mathrm{C}$ and $\mathrm{D}, 131 \mathrm{bp}$ downstream of the alternative splice site that generates isoform $\mathrm{C}$ (Fig. 1A). Although they are inserted at different sites with respect to the shot transcripts, all of the P-element insertions disrupt the protein expression of the long isoforms of Shot and appear to be similar in their axon growth phenotypes (see below).

\section{shot/kak encodes rod-like proteins of varying length that contain one of two alternative C-terminal domains}

The open reading frame in the cDNAs that we initially characterized lacked 3' stop codons, and Northern blot analysis revealed the shot mRNAs to be $\sim 17 \mathrm{~kb}$ in size [Strumpf and Volk (1998), and data not shown]. Therefore, we rescreened both the $\lambda \mathrm{gt} 10$ (Clontech) and the plasmid cDNA libraries (Brown and Kafatos, 1988) using the most $3^{\prime}$ portion of the composite cDNA and isolated overlapping cDNA clones that extended the open reading frame to the $3^{\prime}$ end of shot.

These clones identify additional isoforms of Shot/Kak, the longest of which encodes a 5501 amino acid protein that is almost completely identical to the previously reported 5497 amino acid protein (Gregory and Brown, 1998; Strumpf and Volk, 1998) (Fig. $1 B)$. The central region of this protein is likely to be rod-like and contains 22 triple helical coiled-coil repeats (Strumpf and Volk, 1998) similar to those found in spectrin (Speicher and Marchesi, 1984) and dystrophin (Dubreuil, 1991). The C-terminal globular domain contains two EF-hand motifs (Ikura, 1996). The C-terminal globular domain also contains a short stretch of sequence homology to the mammalian growth arrest-specific 2 (Gas2) protein (Schneider et al., 1988). Gas2 is a cytoskeletal protein of unknown function that appears to be associated with microfilaments in cultured cells and is highly induced in cultured fibroblasts during serum starvation (Brancolini et al., 1992).

The cDNA sequences that we isolated for the $3^{\prime}$ end of the shot gene reveal that the central rod region is also alternatively spliced (Figs. 1, 3A). Seven of eight cDNA clones predict an isoform that shares the same central rod sequence reported previously (Strumpf and Volk, 1998). The other clone encodes a 300 amino acid sequence within the central rod region, as previously reported for Shot/Kak isoforms A and B (Gregory and Brown, 1998).

We also isolated a cDNA in which the sequence for the 300 amino acid region is spliced to a novel sequence that encodes a globular domain of 436 amino acids (Fig. 3A). This 436 amino acid domain shows low homology to the six tandem repeat domains in the C-terminal globular region of plectin (Liu et al., 1996) and is unlikely to form extensive coiled-coil structure. Although it still contains considerable coiled-coil forming sequence (Lupas, 1997), this truncated isoform lacks the 22 triple helical repeats found in the longer isoforms. By comparing the known lengths of plectin (Foisner and Wiche, 1987) and dystrophin (Pons et al., 1990) proteins, and the relative lengths of coiled-coil forming sequence in Shot, plectin and dystrophin (Lupas, 1997), we infer that the truncated isoforms of Shot are $\sim 75 \mathrm{~nm}$ long and the long isoforms of Shot are $\sim 200-220 \mathrm{~nm}$ long. Thus, shot encodes rod-like proteins of varying length with different $\mathrm{C}$-terminal domains, as well as different predicted actin binding properties.

The sequence of the C-terminal domain in the longer Shot isoforms matches the C-terminal sequences of several vertebrate proteins (Seki et al., 1997; Strumpf and Volk, 1998), including the full-length sequence of mouse ACF7 recently reported in GenBank. The sequence of the EF-hand and GAS2 domains are particularly well conserved (Fig. $3 B$ ). Sequencing of the shot cDNAs also reveals diversity in this C-terminal domain (Fig. $3 B$ ). The C-terminal sequence after the Gas2 homology domain is alternatively spliced, with the variant reported here being a closer match to the vertebrate proteins.

Taken together, we have cloned overlapping cDNAs that predict multiple isoforms of Shot/Kak (Fig. $3 B$ ) and greatly expand the potential functional diversity of this gene. The gene encodes rod-like proteins of varying lengths, only some of which contain complete $\mathrm{N}$-terminal actin binding domains. These proteins contain two different classes of globular C-terminal domains, which in plakins mediate protein-protein interactions. By analogy, the different Shot proteins may therefore interact with diverse cytoskeletal targets.

\section{The long isoforms of Short stop are expressed in axons}

The previously reported descriptions of kak report its expression at high levels in epidermal muscle attachment cells and chordotonal organ support cells and at lower levels in epidermis and in motor axon terminals, but did not analyze its expression in the nervous system during axon development. shot mRNAs are expressed also in the CNS and PNS during embryonic stages 13 and 14 when most axon outgrowth begins, and this expression persists

\section{$\leftarrow$}

Black background indicates sequence identities between Drosophila and vertebrate proteins; gray background indicates sequence similarities. Gaps to allow a maximal alignment are marked by dashes. The amino acid residue numbers for dShot are based on a sequence that includes the sequence of isoform A (Fig. 2A), the long rod domain, and the 300 amino acid sequence found in the middle of some Shot proteins $(A)$. The EF-hand sequence reported previously (Strumpf and Volk, 1998) does not completely match genomic sequence and the EF-hand consensus and has been corrected in this figure. The alternatively spliced region after the GAS2 domain is indicated. 

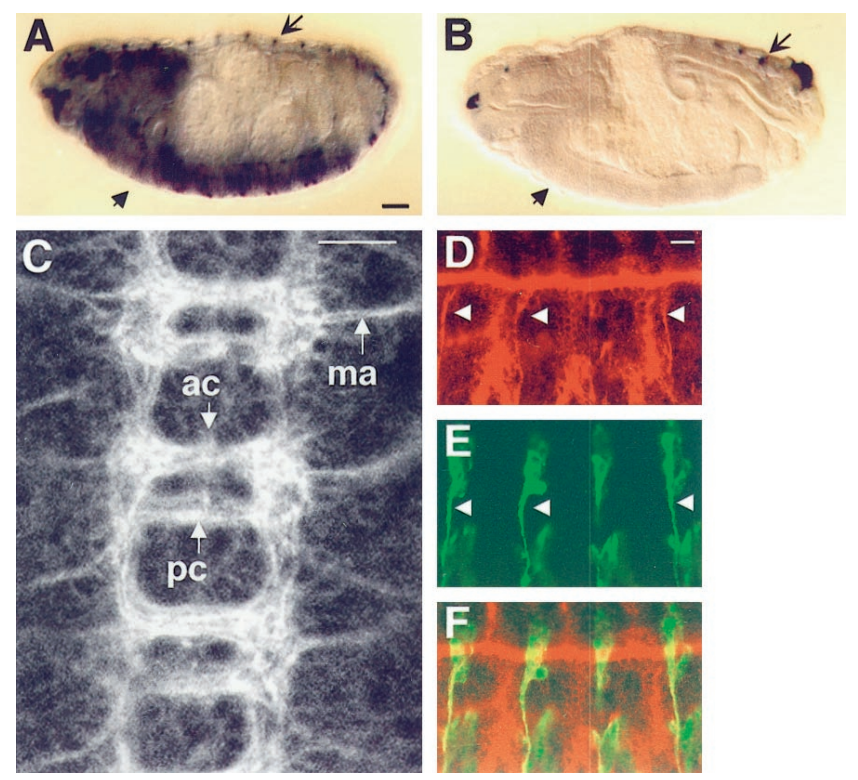

Figure 4. Only Shot isoforms A and B, those that contain complete actin binding domains, are detectably expressed in the nervous system, and the long isoforms of Shot are present in axons. $A$, In situ hybridization with a cDNA probe containing $5^{\prime}$ sequence derived from the actin binding isoform $\mathrm{A}$ and the first half of the actin binding domain coding sequence shared also by isoform B reveals transcripts in the CNS (arrow) and muscle attachment cells (concave arrow) at stage 17 as well as earlier (data not shown). $B$, Whole-mount in situ hybridization to a stage 17 embryo with a cDNA probe containing exons specific for isoforms $C$ and $D$ reveals comparable levels of expression in muscle attachment cells (concave arrow), but no detectable expression in the CNS (arrow). Scale bar, 30 $\mu \mathrm{m}$. $C$, Confocal $(1 \mu \mathrm{m})$ section of a stage 14 wild-type embryo stained with polyclonal anti-Kak (Strumpf and Volk, 1998). This antibody recognizes epitopes in the rod domain present in the long isoforms of Shot/ Kak. Axons in the anterior commissure $(a c)$ and posterior commissure $(p c)$, as well as motor axons $(m a)$ and longitudinal axons, contain Shot/ Kak. Scale bar, $10 \mu \mathrm{m}$. D, A confocal section showing Shot/Kak (red, arrowhead) protein in the sensory axons emanating from the dorsal cluster of sensory neurons in each abdominal hemisegment. The antiserum also recognizes Shot protein in epithelial cells and a nonspecific epitope in tracheal lumen. The epithelial and sensory axon staining disappears in shot mutants, but the tracheal lumen staining does not. Scale bar, $10 \mu \mathrm{m}$. $E$, The dorsal cluster sensory neurons and their axons in the same section revealed with mAb 22C10 (Fujita et al., 1982). $F$, Merge of $D$ and $E$.

to later stages of embryonic development when synapse formation occurs (Fig. 4A). Intriguingly, mRNAs encoding the actin binding domain containing isoforms $\mathrm{A}$ and $\mathrm{B}$ are expressed in the CNS (Fig. $4 A$ ), but mRNAs encoding isoforms $\mathrm{C}$ and $\mathrm{D}$ are not detectably expressed in the CNS (Fig. 4B). The mRNAs encoding isoforms $\mathrm{A}$ and $\mathrm{B}$ are also transiently expressed in the developing PNS at stage 13 (data not shown). This difference in the expression of the actin binding and non-actin binding isoforms parallels the differences observed in the expression of neuronal, actin binding and epidermal, non-actin binding isoforms of BPAG1/dystonin. Otherwise, the mRNAs encoding the $\mathrm{N}$-terminal isoforms reported here, and those identified previously (Strumpf and Volk, 1998), are expressed in identical patterns in the embryo: in the epidermis at low levels and in muscle attachment cells at high levels.

An antiserum against Kak (Strumpf and Volk, 1998) was used to investigate whether the Shot/Kak proteins are expressed in developing axons. This antibody is raised against epitopes present in the 22 triple helical repeats of the long isoforms of Shot/Kak. Therefore it does not detect the shorter isoforms of Shot that we have identified but recognizes a major band of at least $400 \mathrm{kDa}$ on Western blots (Strumpf and Volk, 1998). In embryos, Shot/Kak protein can be detected in axons in the CNS and PNS (Fig. $4 C-F)$. Although the expression level in growth cones is difficult to determine because Shot is expressed in surrounding epidermal cells, Shot is present in CNS axons as early as stage 12 (data not shown) and can be detected in the intersegmental nerve (ISN). In addition, it accumulates in cortical regions of the neuronal cell bodies of chordotonal and dorsal cluster sensory neurons (Fig. $4 D-F)$, consistent with an association with the actin cytoskeleton.

Shot/Kak protein expression in neurons, epidermis, and epidermal muscle attachment cells cannot be detected in $s h o t^{3}$, shot $^{\mathrm{P} 1}$, shot ${ }^{\mathrm{P} 2}$, and $k a k^{\mathrm{P} 2}$ mutant embryos. shot ${ }^{1}$ and shot $^{2} \mathrm{mu}-$ tants still express normal levels of Shot protein, consistent with their relatively weaker mutant phenotypes. The phenotypes of shot $^{\mathrm{P} 1}$ and shot $^{\mathrm{P} 2}$ insertion mutants are also somewhat weaker than the phenotypes of $s h o t^{3}$ and $k a k^{\mathrm{P} 2}$ insertion mutants, suggesting that Shot proteins may perhaps be present in the nervous system in these mutants at levels not detected by this antibody. The Kak antiserum also reacts strongly with an antigen present in the wall of the tracheal lumen (Fig. 4D); this cross-reactivity remains in all of the shot mutant alleles tested.

\section{Short stop is required for the continued extension of all sensory axons, rather than their navigation}

We identified shot in a screen for mutations affecting sensory axon morphology (Kolodziej et al., 1995). shot ${ }^{3}$ mutant embryos stained with mAb $22 \mathrm{C} 10$, a reagent that labels all sensory neurons and their axons (Fujita et al., 1982), are revealed to contain only rudimentary sensory axons (Kolodziej et al., 1995). Sensory axon bundles are more variably affected in $s h o t^{2}$ mutants, and defects cannot be detected with the mAb 22C10 antibody in shot ${ }^{1} \mathrm{mu}-$ tants (Kolodziej et al., 1995). shot mutants appear normal with respect to other aspects of neuronal differentiation and viability.

To gauge the relative severity of the shot mutations more precisely, we compared the length of a bundle of four sensory axons in wild-type and mutant embryos. mAb 49C4 specifically recognizes four of the five lateral chordotonal $(\mathrm{LCH})$ neurons and their axons (Kolodziej et al., 1995). In wild-type embryos, the LCH sensory axons grow anteriorly, turn ventrally when they join the ISN, and extend into the CNS by stage 16. In shot ${ }^{1}$ embryos, the LCH axons arrest at variable points within the ISN (Kolodziej et al., 1995). As quantitated here, the LCH axons in $s h o t^{2}$ and shot ${ }^{3}$ are more severely affected (Table 1), and the LCH axons in shot ${ }^{3}$ mutants almost always stall before advancing far along the ISN $(93 \%)$. In these severe alleles, the LCH axons never extend to the CNS border. The P-element insertions $k a k^{\mathrm{P} 1} / k_{a k} \mathrm{P}^{\mathrm{P}}$, shot ${ }^{\mathrm{P} 1}$, and shot $^{\mathrm{P} 2}$ affect $\mathrm{LCH}$ axon growth on average less severely than the $s h o t^{2}$ and $s h o t^{3}$ alleles but show a similar range of stall phenotypes (Table 1). Although the long form of Shot protein cannot be detected in these P-element mutant embryos (Fig. 4 and data not shown), these slight differences in phenotype may reflect low levels of the long Shot proteins or other isoforms still present in some of the P-element alleles.

The shorter axons observed in shot mutants could reflect a delay in axonogenesis or a defect in the ability of growth cones to advance. Dye filling of the chordotonal neurons allowed us to resolve details of the timing of axonogenesis and the morphology of individual axons and growth cones in wild-type and mutant embryos. In wild-type embryos, axonogenesis in the LCH neurons occurs before stage $15(n=14)$ (Fig. $5 A)$. In shot $^{2} /$ shot $^{3}$ mutant embryos, the $\mathrm{LCH}$ neurons also extend a growth cone 


\begin{tabular}{|c|c|c|c|c|c|}
\hline Allele & Dorsal $^{a}$ & ISN border $^{b}$ & $\mathrm{ISN}^{c}$ & CNS border ${ }^{d}$ & $\mathrm{CNS}^{e}$ \\
\hline$W T$ & $0(n=98)^{f}$ & 0 & 0 & 0 & 100 \\
\hline$W T$ & $0(n=21)^{g}$ & 0 & 0 & 5 & 95 \\
\hline$k a k^{P 1}$ & $0(n=56)^{f}$ & 27 & 55 & 18 & 0 \\
\hline $\operatorname{shot}^{P 2}$ & $2(n=91)^{f}$ & 50 & 46 & 2 & 0 \\
\hline $\operatorname{shot} t^{P 1}$ & $1(n=91)^{f}$ & 40 & 69 & 0 & 0 \\
\hline$s h o t^{2}$ & $0(n=112)^{f}$ & 68 & 32 & 0 & 0 \\
\hline $\operatorname{shot}^{2} / \operatorname{shot}^{3}$ & $0(n=13)^{g}$ & 90 & 7 & 0 & 0 \\
\hline $\operatorname{shot}^{3}$ & $0(n=98)^{f}$ & 93 & 7 & 0 & 0 \\
\hline $\operatorname{shot}^{3}$ & $0(n=7)^{g}$ & 63 & 47 & 0 & 0 \\
\hline
\end{tabular}

${ }^{a}$ Dorsally directed axon bundles. Numbers in parentheses refer to hemisegments examined.

${ }^{b}$ These axon bundles extend anteriorly toward the ISN and stall or fail to reach the ISN.

${ }^{c}$ These axon bundles traveled a significant distance in the ISN.

${ }^{d}$ These axon bundles reached the CNS but did not appear to penetrate it.

${ }^{e}$ Wild-type axon bundles entered the CNS and formed arborizations.

${ }^{f}$ These axon bundles were visualized using mAb 49C4.

${ }^{g}$ These axons were visualized by dye-filling single LCH neurons.

toward the ISN by early stage $15(n=6)$ (Fig. $5 D)$. By early stage 16, the LCH axons in wild-type embryos reach the CNS (Table 1, Fig. 5C). By early stage 16 , no $\mathrm{LCH}$ axons in $s h o t^{\mathrm{P} 2}$, shot ${ }^{3}$, or $s h o t^{2} /$ shot $^{3}$ mutant embryos reach the CNS (Table 1, Figs. 5E, F). Therefore, the stalled axon phenotype detected in stage 16 shot embryos does not reflect a delay in axonogenesis.

The inability of growth cones to advance in shot mutant embryos could reflect a defect in the formation of actin-based structures known to be important for growth cone motility, such as filopodia or lamellopodia. We found that the LCH axon morphologies observed in shot mutant embryos are indistinguishable from those of wild-type embryos at the same point in the axon trajectory (Fig. 5). LCH growth cones in wild-type embryos extend numerous fine filopodia and have a wide lamellopodium before they join the ISN (Fig. $5 A$ ). As they advance along the ISN, they become narrower and less complex (Fig. $5 B$ ). These morphological transitions are also observed in shot mutant embryos, with the growth cones adopting the general morphology of wild-type growth cones at the place where they stall (Figs. 5E, $F$ ). Growth cones that fail to contact the ISN are more complex than those that stall within the ISN. The direction of axon growth is also unaffected in shot mutant embryos. Thus, growth cones form normally and orient correctly in shot mutant embryos but fail to continue advancing. Although growth cone morphology appears to be unaffected, we often observe defects in LCH dendrite morphology in $s h o t^{\mathrm{P} 2}$, shot ${ }^{3}$, and $s h o t^{2} /$ shot $^{3}$ mutant embryos $(n=8 / 30)$ (Fig. 5D,E). This is consistent with the description of dendrite detachment reported in kak mutants (Prokop et al., 1998).

\section{Short stop is required for the continued extension of all motor axons, rather than their navigation}

In the abdominal hemisegments of wild-type embryos, 31 motor axons innervate 30 muscle fibers in a stereotyped pattern (Sink and Whitington, 1991; Landgraf et al., 1997). These motor axons are organized into nerve bundles that innervate different muscle fields. The main ISN motor axons innervate the dorsal muscles, the intersegmental nerve $b$ (ISNb) motor axons innervate ventral muscles, and the segmental nerve a ( $\mathrm{SNa}$ ) motor axons innervate ventrolateral muscles (Sink and Whitington, 1991).

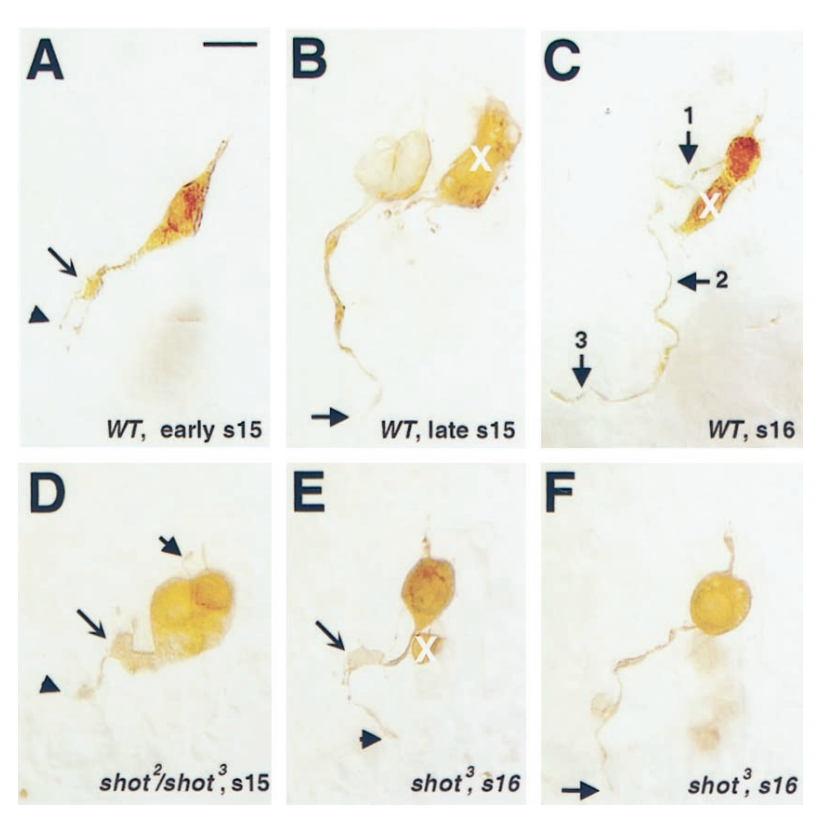

Figure 5. Lateral chordotonal sensory axons are truncated in shot mutants. $A$, An LCH5 axon in a very early stage 15 wild-type embryo (WT, early s15) extends anteriorly before reaching the ISN (very early stage 15) and makes a characteristically wide growth cone (arrow) with extensive filopodia (arrowhead). LCH5 refers to the fifth most anterior chordotonal neuron in the cluster of five $\mathrm{LCH}$ neurons. $B, \mathrm{LCH} 1$ and $\mathrm{LCH} 2$ axons in a stage 15 wild-type embryo (WT,late s15) join the ISN and extend ventrally. The growth cones are narrower and less complex during growth in the ISN (arrow). $C$, An LCH5 axon in a stage 16 wild-type embryo (WT,s16) extends anteriorly (arrow 1), turns ventrally and extends along the ISN (arrow 2), and enters the CNS and turns anteriorly (arrow 3). D, LCH4 and LCH5 axons in a very early stage 15 shot $^{2} /$ shot $^{3}$ mutant embryo also display wide growth cones (arrow) with several filopodia (arrowhead). Neither the timing of axonogenesis nor the morphology of the growth cones is affected (compare $D$ with $A$ ). However, the dendrites (short arrow) are abnormally short and bent compared with wild type. $E, F$, LCH5 axons in stage 16 shot $^{3}$ mutant embryos. Axons stall either before reaching the ISN $(E)$ or after a short ventral projection within the ISN $(F)$. Growth cone morphology is normal (compare $E$ with $A$, and $F$ with $B)$. All images are photomontaged from in-focus regions of dye-filled LCH5 neurons. Anterior is to the left; dorsal is up. Labeled non-neuronal cells are marked with a white $X$. Scale bar, $10 \mu \mathrm{m}$. 
Table 2. Percentages of normal and defective motor axon bundles in wild-type and shot mutant embryos

\begin{tabular}{|c|c|c|c|c|c|c|}
\hline Allele $^{a}$ & $\mathrm{WT} \mathrm{ISN}^{b}$ & 1 absent $^{c}$ & 1-2 absent & $1-3$ absent $^{d}$ & Early stall $^{e}$ & ISN crossover \\
\hline$W T$ & $100(n=87)$ & 0 & 0 & 0 & 0 & 0 \\
\hline$s h o t^{3}$ & $4(n=79)$ & 3 & 68 & 24 & 1 & 0 \\
\hline $\operatorname{shot}{ }^{2} / \operatorname{shot}^{3}$ & $1(n=77)$ & 6 & 48 & 43 & 0 & 1 \\
\hline $\operatorname{shot}^{3} / D f$ & $0(n=112)$ & 0 & 40 & 42 & 17 & 1 \\
\hline
\end{tabular}

\begin{tabular}{|c|c|c|c|c|c|}
\hline Allele & WT SNa ${ }^{f}$ & One branch missing ${ }^{g}$ & Both branches absent & Early stall $^{h}$ & Bypass or misrouted $^{i}$ \\
\hline$W T$ & $100(n=86)$ & 0 & 0 & 0 & 0 \\
\hline$s h o t^{3}$ & $11(n=76)$ & 33 & 38 & 17 & 1 \\
\hline $\operatorname{shot}{ }^{2} / \operatorname{shot}^{3}$ & $25(n=63)$ & 46 & 28 & 0 & 0 \\
\hline $\operatorname{shot}^{3} / D f$ & $4(n=114)$ & 24 & 60 & 8 & 4 \\
\hline
\end{tabular}

\begin{tabular}{lccccc}
\hline Allele & WT ISNb & $\begin{array}{l}\text { Stall in ventral } \\
\text { muscle field }\end{array}$ & $\begin{array}{l}\text { Stall at muscle } \\
\text { field border }\end{array}$ & Absent & $\begin{array}{l}\text { One connection } \\
\text { missing }^{l}\end{array}$ \\
\hline$W T$ & $82(n=92)$ & 0 & 0 & 0 & 18 \\
shot $^{3}$ & $4(n=77)$ & 75 & 14 & 5 & 0 \\
shot $^{2} /$ shot $^{3}$ & $2(n=65)$ & 57 & 30 & 6 & 0 \\
shot $^{3} / D f$ & $0(n=105)$ & 61 & 20 & 7 & 0 \\
misrouted $^{m}$
\end{tabular}

${ }^{a}$ The deficiency is $D f(2 R) C X 1$.

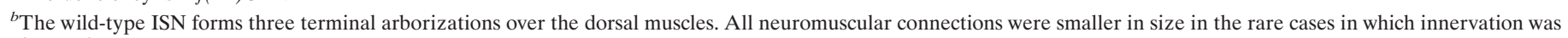
observed.

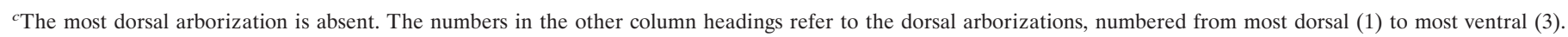

${ }^{d}$ The ISN stalls in the dorsal muscle field and fails to form any arborizations.

${ }^{e}$ The ISN stalls just before entering the dorsal muscle field.

${ }^{f}$ The wild-type SNa forms two branches, which innervate lateral muscles. In mutant embryos, we scored the SNa as wild type if it formed two branches.

${ }^{g}$ The dorsal branch was missing in the vast majority of these cases, and the lateral branch grew along the border of the ventral muscles.

${ }^{h}$ The SNa stalled over the ventral muscles or was absent.

${ }^{i}$ The SNa innervated the adjacent segment or showed an abnormal branching pattern.

${ }^{j}$ The wild-type ISNb forms connections with ventral muscles 12, 13, 6/7. These connections were reduced in size when they were observed in shot mutants.

${ }^{k}$ The ISNb stalls somewhere between muscle 6 (the ventral border of the ventral muscle field) and muscle 13.

${ }^{l}$ One of the normal ISNb connections, usually the 6/7 connection, could not be seen.

${ }^{m}$ The ISNb failed to defasciculate from the ISN, or it innervated the lateral muscles or the wrong part of the ventral muscles.

shot was first identified as a gene specifically required for the outgrowth of the ISN and ISNb motor axons; SNa development was reported to be normal in $s h t^{1}$ mutants (Van Vactor et al., 1993). ISN motor axons in shot ${ }^{1}$ mutant embryos generally arrest near the dorsal trunk of the trachea, just before they would make their two most dorsal arborizations. The ISNb motor axons arrest in the middle of the ventral muscle field. Thus, shot was suggested to be required for the extension of only a subset of motor axons beyond a well defined point in their development (Van Vactor et al., 1993).

This previous analysis of shot's role in motor axon development is based on $s h o t^{1}$, which still expresses Shot protein (data not shown) and has a weaker effect on sensory axon development than the other shot alleles (Kolodziej et al., 1995). Other mutations in $k a k$ also affect motor axon development but affect synapse formation without affecting axon outgrowth (Prokop et al., 1998). Thus, kak was proposed to be specifically involved in synapse formation and not to be required earlier in motor axon development. To investigate motor axon development in a stronger allele, we therefore analyzed motor axons in $s h o t^{3}$ and $s h o t^{3} /$ $D f(2 R) C X 1$ mutant embryos, because $s h o t^{3}$ appears to affect the LCH axons most severely among the alleles that lack detectable Shot proteins.

In late stage 16/stage 17 wild-type embryos stained with mAb 1D4, the motor axons in the ISN pathway have reached the dorsal muscles and formed three terminal arborizations. The motor axons in the SNa pathway have reached the ventrolateral muscles and bifurcated into two branches, a lateral branch that extends posteriorly along the border of the ventral muscle field and a dorsal branch that extends more dorsally into the ventrolateral muscle field. The ISNb motor axons have defasciculated from the ISN and have formed contacts with muscles 12, 13, and 6/7.

In late stage $16 /$ stage 17 shot $^{3}$ mutant embryos, $90-100 \%$ of the motor axons (Table 2) in all three major pathways (ISN, SNa, and ISNb) stall prematurely (Figs. 6, 7). The ISN motor axons not only lack terminal arborizations (Prokop et al., 1998), but do not reach the muscles that they normally innervate (Fig. 6). Although $\mathrm{SNa}$ development appears normal in shot $^{1}$ embryos, the $\mathrm{SNa}$ motor axons in stronger shot mutants generally fail to form both branches, and they often stall at the entry to the ventrolateral muscles (Figs. 6, 7). The ISNb motor axons defasciculate normally from the ISNb and correctly target the ventral muscle field, but they stall in the ventral muscle field or before they enter it (Figs. 6, 7). The place where the motor axons in a given pathway stall is variable and does not suggest as well defined an arrest point as proposed earlier from studies of the $s h t^{1}$ allele (Van Vactor et al., 1993). Some SNa and ISNb motor axon bundles fail to exit the CNS successfully or stall earlier than the muscle field entry points, and some ISN motor axon bundles (17\%) stall well before the dorsal muscles in $\operatorname{shot}^{3} / D f(2 R) C X 1$ embryos (Table 2). Thus, shot may also be required for motor axon extension before entry into the muscle fields. The rare axons that reach their 


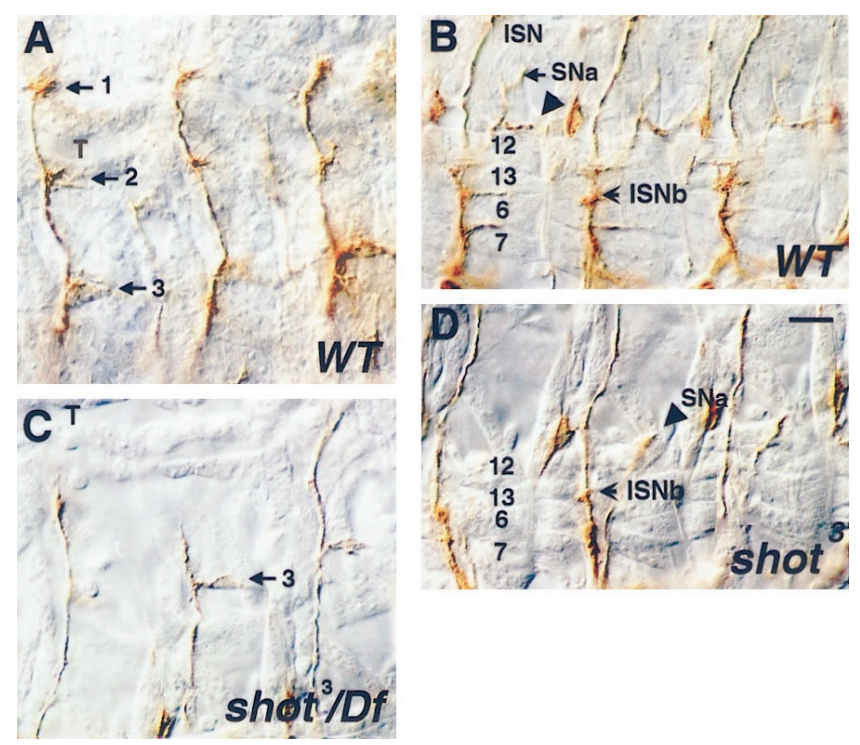

Figure 6. Motor axons stall in shot mutant embryos. A, A dorsal section of three abdominal hemisegments in a late stage 16 embryo stained with mAb 1D4 (Van Vactor et al., 1993) to visualize the motor axons. Motor axons in the ISN (arrows) form three terminal arborizations over the dorsal muscles. $T$, Trachea. $B$, A ventrolateral section of three abdominal hemisegments in a late stage 16 embryo stained with mAb 1D4. The ISN extends dorsally. The SNa motor axons contact lateral muscles and bifurcate into dorsal (arrow) and lateral (arrowhead) branches. The ISNb motor axons (concave arrow) make contacts with muscles 12 and 13 and the cleft between muscles 6 and 7. C, ISN motor axons (arrow) typically stall at variable positions in the dorsal muscle field in $s h o t^{3} / D f(2 R) C X 1$ mutant embryos, but generally form the third arborization. $D$, The $\mathrm{SNa}$ (arrowhead) and ISNb motor axons (concave arrow) stall before reaching their muscle targets in a late stage 16 shot $^{3}$ mutant embryo. WT, Wild type.

$\mathbf{A}$

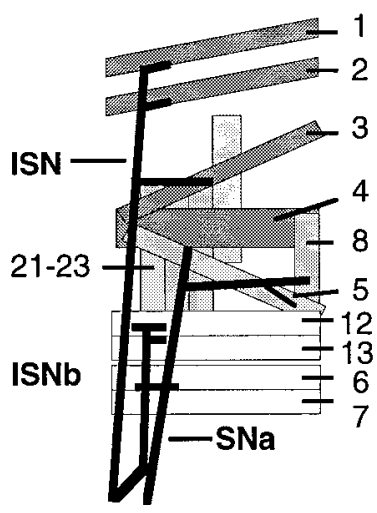

B

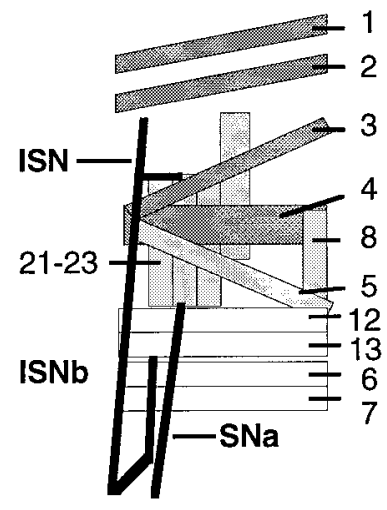

Figure 7. A schematic of the pattern of muscle innervation in wild-type $(A)$ and shot mutant embryos $(B)$. Motor axons in shot mutants stall before reaching their muscle targets. Muscle fibers are numbered and shaded according to whether they are dorsal (dark gray), lateral (light gray), or ventral (white). Motor axon bundles (ISN, ISNb, and $S N a$ ) are in black.

muscle targets generally fail to form the arborizations indicative of neuromuscular junction formation, or they form arborizations of reduced size, as seen in weaker kak mutants (Prokop et al., 1998). shot does not appear to be required for motor axons to choose the appropriate pathways or for selective fasciculation.

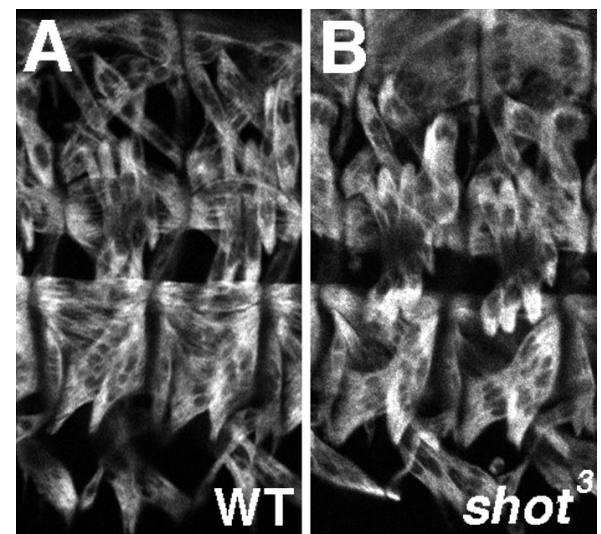

Figure 8. Muscle patterning is normal in shot null mutant embryos. A, A confocal section showing the ventral and lateral muscles in two abdominal hemisegments of a stage 16 wild-type embryo $(W T)$ stained with a monoclonal antibody against myosin heavy chain. $B$, A similar section showing the ventral and lateral muscles in two abdominal hemisegments of a shot ${ }^{3}$ null mutant embryo.

Motor axons in shot mutant embryos complete a substantially greater portion of their trajectory than do sensory axons. In wild-type embryos, sensory neurons in the dorsal and lateral PNS clusters extend axons along the ISN motor axon pathway and fasciculate with the ISN motor axons. Because the ISN motor axons extend beyond the lateral chordotonal cluster in shot mutant embryos, it is unlikely that defects in the extension of the motor axons explain defects in the growth of sensory axons in shot mutant embryos. The ability of sensory and motor axons to fasciculate appears normal in shot mutant embryos.

The same range of defects is seen in $\operatorname{shot}^{3} / D f(2 R) C X 1$ mutant embryos as compared with shot ${ }^{3}$ mutants alone, and the frequency of the more severe phenotypes is only modestly enhanced (Table 2). These data, taken together with the absence of detectable long isoforms of Shot in homozygous shot ${ }^{3}$ mutant embryos, suggest that $\operatorname{shot}^{3}$ is a null allele. Thus, Shot is only essential in motor axon development for the later steps of outgrowth. If shot were required for the initial stages of motor axon outgrowth, one would expect to see some examples of segments with no mAb1D4-stained axon bundles in the most severe alleles.

It has been reported previously that shot mutants are defective in muscle attachment because of defects in the formation of epidermal attachment cells. Moreover, Shot appears to be important for stabilizing the cytoskeleton of these attachment cells against contractile forces exerted by muscle. On becoming contractile (stage 17 embryos or later), muscles rip loose from their attachment sites. Because defects in muscle organization could affect motor axon growth and targeting, we examined muscle morphology in shot $^{3}$ null mutant embryos using an antibody against myosin. Muscle number and organization were normal in (10 of 10) late stage 16 shot $^{3}$ mutant embryos (Fig. 8), a stage at which motor axons have reached their target muscles in wild-type embryos. Muscles are also normal in embryos homozygous for the weaker shot $^{1}$ allele (Van Vactor et al., 1993). Moreover, the expression of connectin, which marks a subset of lateral muscles (Gould and White, 1992; Nose et al., 1992), is also normal in shot mutant embryos (data not shown). We conclude that defects in muscle development probably do not contribute to the motor axon growth defects observed. 


\section{DISCUSSION}

\section{Short stop proteins comprise a novel, neuronally expressed plakin subfamily required for motor and sensory axon growth}

Shot/Kak proteins contain an N-terminal domain, a central rod domain, and a $\mathrm{C}$-terminal globular domain. We have shown that the predicted actin binding properties of the $\mathrm{N}$-terminal domains, the length of the rod, and the structure of the C-terminal domain are all varied by the use of different transcriptional start points or alternative splicing. The diversity in these three key structural features, the selective expression of isoforms containing only complete predicted actin binding domains in the nervous system, and the Shot axon growth defects together suggest that a complex mixture of Shot proteins may function to organize other proteins spatially with respect to the actin cytoskeleton during sensory and motor axon extension.

Shot/Kak proteins are most closely related to the plakin family (Ruhrberg and Watt, 1997). They also share some structural features with dystrophin (Gregory and Brown, 1998; Strumpf and Volk, 1998), the rod-like actin binding protein altered in Duchenne muscular dystrophy (Koenig et al., 1988) that links the actin cytoskeleton in muscle to the membrane (Michalak and Opas, 1997). Plakins comprise a family of rod-like proteins that crosslink actin and intermediate filaments and are required for the integrity of skin and sensory axons (Guo et al., 1995; McLean et al., 1996; Fuchs and Cleveland, 1998). These proteins (BPAG1, plectin, desmoplakin, and envoplakin) localize to membrane attachment sites for intermediate filaments and some also bind microtubules (Fuchs and Cleveland, 1998). In their overall structure, and as we show here, the presence of isoforms with varied predicted actin binding properties, Shot/Kak proteins resemble other plakins.

Variations in the predicted actin binding properties in additional isoforms of Shot identified here likely contribute significantly to Shot's functions in different cell types. Isoforms C and D lack either part or all of the predicted N-terminal actin binding domain. Shot isoforms C and D appear to be epithelial and muscle attachment cell specific and are not detectably expressed in the nervous system (Fig. 4). Conceivably, the N-terminal domains of these isoforms may interact with cytoskeletal proteins other than actin or may bind to the actin binding isoforms, by analogy to other plakins (Ruhrberg and Watt, 1997; Yang et al., 1999). The apparent absence of the C and D isoforms from the nervous system suggests that Shot proteins may interact differently with the neuronal and epithelial actin cytoskeletons. These differences may reflect cell type-specific differences in Shot function, enabling neuronal growth cones to be motile and enabling the cortical actin cytoskeleton in epithelial cells to resist mechanical stress.

Shot/Kak proteins and their vertebrate and $C$. elegans homologs are distinguished from other plakins in that the longest isoforms contain a signature C-terminal domain with homology to the Gas2 protein (Schneider et al., 1988; Strumpf and Volk, 1998). The function of this domain is unknown, but by analogy to the other plakins, it may interact with other cytoskeletal proteins to organize them relative to the actin cytoskeleton. We have determined that this C-terminal domain is also alternatively spliced, which may further enhance the diversity of such interactions. Two EF-hand $\mathrm{Ca}^{2+}$-binding motifs are also found in the C-terminal domain of the long Shot isoforms, as well as in dystrophin. shot also encodes shorter rod-like proteins that contain different C-terminal domains. Variation of the rod length likely alters the spacing of different complexes containing the $\mathrm{N}$-terminal and $\mathrm{C}$-terminal domains, and varying the $\mathrm{C}$-terminal domain likely alters the nature of these complexes. These short Shot proteins lack the 22 heptad repeats found in the long isoforms (Strumpf and Volk, 1998) but are predicted to contain considerable coiledcoil forming sequence (Lupas, 1997). Their C-terminal domain most closely resembles that of plectin (Liu et al., 1996), but the functional significance of this homology is unknown.

\section{Short stop is required for sensory and motor axon extension, rather than navigation}

We show here that shot is required for the development of all motor and sensory axons, a process that occurs normally in weaker kak alleles (Prokop et al., 1998). The structure of Shot and its expression in axons suggest that shot is required in neurons for axon extension, consistent with observations that shot acts cell autonomously in mushroom body neurons to promote axon fasciculation and growth (Lee and Luo, 1999). Although defects in substrate cells could conceivably contribute to the severity of the phenotypes observed, muscles do not detectably express Shot and appear to differentiate normally during motor axon growth in shot mutant embryos. Although neuronal isoforms of BPAG1 are involved in maintaining the axon cytoskeleton (Brown et al., 1995a,b), Shot is the first plakin-like molecule to have a demonstrated developmental role in axon extension.

Our results suggest that shot is involved in selected later axon extension events rather than in early steps of growth cone formation or axon outgrowth per se. In shot mutant embryos lacking detectable Shot proteins, chordotonal neurons form growth cones, extend at the appropriate time, and grow toward the ISN, but they either fail to join the nerve or stall after a short ventral extension. Motor axons arrest near their target muscle fields but generally leave the CNS, select the appropriate pathways, and defasciculate normally. The defects are more severe than previously reported for weaker alleles but are consistent with a general defect in the ability of motor axons to grow into or perhaps recognize muscle target fields. Axon tracts in the CNS of shot mutants are only modestly reduced in diameter (Prokop et al., 1998), further suggesting that Shot plays a role in only a subset of axon growth processes.

Growth cone advance is disrupted in shot mutants, yet the morphology of stalled growth cones in mutants appears similar to motile growth cones in wild-type embryos. Thus, Shot is unlikely to be essential for actin polymerization, or its regulation by Rho family GTPases, because these processes are required for the generation of filopodia and lamellopodia (Hall, 1998). Despite the lack of obvious defects in such actin-based structures, Shot's interactions with actin are nonetheless likely to be critical for growth cone motility, because only isoforms with predicted actin binding domains are detectably expressed in neurons. Mutants in profilin, an actin binding protein, also show defects in growth cone motility, but form filopodia and lamellopodia (Wills et al., 1999). Defects in actin-based motility are therefore not always reflected in growth cone morphology.

\section{Short stop may organize proteins in the growth cone during axon development}

The plakin-like structures of Shot proteins suggest that these proteins may link actin to proteins that interact with the C-terminal domains. In particular, Shot may help coordinate the 
actin and microtubule components of the cytoskeleton during sensory or motor axon growth cone advance. Microtubule arrays in epithelial muscle attachment cells are abnormally organized with respect to the actin cytoskeleton in shot mutants (Prokop et al., 1998). Moreover, the mouse $A C F 7$ gene has been reported in a recent GenBank submission (accession number AAD32244) to encode an actin/microtubule cross-linking protein that contains all of the key structural features of the long isoforms of Shot. In the nervous system, Shot appears to be distributed along axons, where it could interact with the microtubule-filled core of the axon cytoskeleton, and the C-terminal of the long Shot isoform is efficiently targeted to axons (S. Lee and P. Kolodziej, unpublished data).

Functional redundancy with other proteins that may coordinate actin and microtubule dynamics in response to guidance cues could explain why sensory and motor axons exhibit normal growth cone morphologies and can partially extend in shot mutants. Several other proteins have recently been discovered to link actin and microtubules (Andra et al., 1998; Togel et al., 1998; de Hostos, 1999; Yang et al., 1999), although they have not yet been implicated in axon growth. Shot's proposed interactions with actin and microtubules could be a target of many, but not all, guidance systems. A combination of functional redundancy in such a key cell biological role and involvement in a subset of guidance systems could explain why some features of axon development are normal in shot mutants, yet the phenotypes are more penetrant and less cell type-specific than those of mutations in known Drosophila guidance receptors (Desai et al., 1996; Kolodziej et al., 1996; Krueger et al., 1996; Hoang and Chiba, 1998; Kidd et al., 1998).

Alternatively, defects in Shot's interactions with other proteins may underlie the shot axon growth phenotypes. Shot may localize or modulate selected signaling molecules permissive for continued sensory and motor axon growth. Other classes of proteins that may also interact with Shot include membrane proteins and components of membrane ruffles, actin-based structures involved in cell motility. Epidermal attachment cells in shot mutants fail to localize Vein, an extracellular matrix protein whose localization depends on surface receptors expressed by these cells (Strumpf and Volk, 1998). Gas2, which shares limited homology to the Shot C-terminal domain, partially colocalizes to membrane ruffles in cultured fibroblasts on serum induction (Brancolini and Schneider, 1994).

The length of the long Shot isoforms suggests that they could play a central role in spacing protein assemblies in the growth cone or axon. Based on comparison of the lengths of the coiledcoil regions of Shot and dystrophin (Lupas, 1997), and the known $175 \mathrm{~nm}$ lengths of dystrophin determined by electron microscopy (Pons et al., 1990), Shot proteins could be as long as $220 \mathrm{~nm}$, a substantial fraction of the $500 \mathrm{~nm}$ width of a Drosophila axon. Shot proteins also contain $\mathrm{Ca}^{2+}$-binding domains and may therefore represent another cytoskeletal target for the action of $\mathrm{Ca}^{2+}$ transients, waves of calcium release that appear to regulate growth cone motility (Gomez and Spitzer, 1999). In any event, shot mutants provide a powerful tool for identifying a crucial link in the molecular chain from reception of environmental stimuli to axon extension.

\section{REFERENCES}

Altschul SF, Gish W, Miller W, Myers EW, Lipman DJ (1990) Basic local alignment search tool. J Mol Biol 215:403-410.

Andra K, Nikolic B, Stocher M, Drenckhahn D, Wiche G (1998) Not just scaffolding: plectin regulates actin dynamics in cultured cells. Genes Dev 12:3442-3451.

Bentley D, Toroin-Raymond A (1986) Disordered pathfinding by pioneer neuron growth cones deprived of filopodia by cytochalasin treatment. Nature 323:712-715.

Bernier G, Mathieu M, De Repentigny Y, Vidal SM, Kothary R (1996) Cloning and characterization of mouse ACF7, a novel member of the dystonin subfamily of actin binding proteins. Genomics 38:19-29.

Bier E, Vaessin H, Shepherd S, Lee K, McCall K, Barbel S, Ackerman L, Carretto R, Uemura T, Grell E, Jan LY, Jan YN (1989) Searching for pattern and mutation in the Drosophila genome with a P-lacZ vector. Genes Dev 3:1273-1287.

Brancolini C, Bottega S, Schneider C (1992) Gas2, a growth arrestspecific protein, is a component of the microfilament network system. J Cell Biol 117:1251-1261.

Brancolini C, Schneider C (1994) Phosphorylation of the growth arrestspecific protein Gas2 is coupled to actin rearrangements during $\mathrm{Go} \rightarrow \mathrm{G} 1$ transition in NIH 3T3 cells. J Cell Biol 124:743-56.

Brown A, Bernier G, Mathieu M, Rossant J, Kothary R (1995a) The mouse dystonia musculorum gene is a neural isoform of bullous pemphigoid antigen 1. Nat Genet 10:301-306.

Brown A, Dalpe G, Mathieu M, Kothary R (1995b) Cloning and characterization of the neural isoforms of human dystonin. Genomics 29:777-780.

Brown NH, Kafatos FC (1988) Functional cDNA libraries from Drosophila embryos. J Mol Biol 203:425-437.

Campos-Ortega JA, Hartenstein V (1985) The embryonic development of Drosophila melanogaster. New York: Springer.

de Hostos EL (1999) The coronin family of actin-associated proteins. Trends Cell Biol 9:345-350.

Desai CJ, Gindhart Jr JG, Goldstein LS, Zinn K (1996) Receptor tyrosine phosphatases are required for motor axon guidance in the Drosophila embryo. Cell 84:599-609.

Dubreuil RR (1991) Structure and evolution of the actin crosslinking proteins. BioEssays 13:219-226.

Foisner R, Wiche G (1987) Structure and hydrodynamic properties of plectin molecules. J Mol Biol 198:515-531.

Fuchs E, Cleveland DW (1998) A structural scaffolding of intermediate filaments in health and disease. Science 279:514-519.

Fujita SC, Zipursky SL, Benzer S, Ferrus A, Shotwell SL (1982) Monoclonal antibodies against the Drosophila nervous system. Proc Natl Acad Sci USA 79:7929-7933.

Gomez TM, Spitzer NC (1999) In vivo regulation of axon extension and pathfinding by growth-cone calcium transients. Nature 397:350-355.

Gould AP, White RA (1992) Connectin, a target of homeotic gene control in Drosophila. Development 116:1163-1174.

Gregory SL, Brown NH (1998) kakapo, a gene required for adhesion between and within cell layers in Drosophila, encodes a large cytoskeletal linker protein related to plectin and dystrophin. J Cell Biol 143:1271-1282.

Guo L, Degenstein L, Dowling J, Yu QC, Wollmann R, Perman B, Fuchs E (1995) Gene targeting of BPAG1: abnormalities in mechanical strength and cell migration in stratified epithelia and neurologic degeneration. Cell 81:233-243.

Hall A (1998) Rho GTPases and the actin cytoskeleton. Science 279:509-514.

Hoang B, Chiba A (1998) Genetic analysis on the role of integrin during axon guidance in Drosophila. J Neurosci 18:7847-7855.

Ikura M (1996) Calcium binding and conformational response in EFhand proteins. Trends Biochem Sci 21:14-17.

Kidd T, Brose K, Mitchell KJ, Fetter RD, Tessier-Lavigne M, Goodman CS, Tear G (1998) Roundabout controls axon crossing of the CNS midline and defines a novel subfamily of evolutionarily conserved guidance receptors. Cell 92:205-215.

Koenig M, Monaco AP, Kunkel LM (1988) The complete sequence of dystrophin predicts a rod shaped cytoskeletal protein. Cell 53:219-228.

Kolodziej PA, Jan LY, Jan YN (1995) Mutations that affect the length, fasciculation, or ventral orientation of specific sensory axons in the Drosophila embryo. Neuron 15:273-286.

Kolodziej PA, Timpe LC, Mitchell KJ, Fried SR, Goodman CS, Jan LY, Jan YN (1996) frazzled encodes a Drosophila member of the DCC immunoglobulin subfamily and is required for CNS and motor axon guidance. Cell 87:197-204.

Krueger NX, Van Vactor D, Wan HI, Gelbart WM, Goodman CS, Saito 
H (1996) The transmembrane tyrosine phosphatase DLAR controls motor axon guidance in Drosophila. Cell 84:611-622.

Landgraf M, Bossing T, Technau GM, Bate M (1997) The origin, location, and projections of the embryonic abdominal motorneurons of Drosophila. J Neurosci 17:9642-9655.

Lee T, Luo L (1999) A genetic mosaic system with a repressible cell marker and positively labeled mutant cells for the analysis of gene function in neuronal morphogenesis. Neuron 22:451-461.

Letourneau PC, Marsh L (1984) Growth of neurites without filopodial or lamellopodial activity in the presence of cytochalasin B. J Cell Biol 99:2041-2047.

Lin CH, Forscher P (1995) Growth cone advance is inversely proportional to retrograde F-actin flow. Neuron 14:763-771.

Liu CG, Maercker C, Castanon MJ, Hauptmann R, Wiche G (1996) Human plectin: organization of the gene, sequence analysis, and chromosome localization (8q24). Proc Natl Acad Sci USA 93:4278-4283.

Lundquist EA, Herman RK, Shaw JE, Bargmann CI (1998) UNC-115, a conserved protein with predicted LIM and actin-binding domains, mediates axon guidance in C. elegans. Neuron 21:385-392.

Luo L, Liao YJ, Jan LY, Jan YN (1994) Distinct morphogenetic functions of similar small GTPases: Drosophila Drac1 is involved in axonal outgrowth and myoblast fusion. Genes Dev 8:1787-1802.

Lupas A (1997) Predicting coiled-coil regions in proteins. Curr Opin Struct Biol 7:388-393.

McLean WH, Pulkkinen L, Smith FJ, Rugg EL, Lane EB, Bullrich F, Burgeson RE, Amano S, Hudson DL, Owaribe K, McGrath JA, McMillan JR, Eady RA, Leigh IM, Christiano AM, Uitto J (1996) Loss of plectin causes epidermolysis bullosa with muscular dystrophy: cDNA cloning and genomic organization. Genes Dev 10:1724-1735.

Merritt DJ, Whitington PM (1995) Central projections of sensory neurons in the Drosophila embryo correlate with sensory modality, soma position, and proneural gene function. J Neurosci 15:1755-1767.

Michalak M, Opas M (1997) Functions of dystrophin and dystrophin associated proteins. Curr Opin Neurol 10:436-442.

Nose A, Mahajan VB, Goodman CS (1992) Connectin: a homophilic cell adhesion molecule expressed on a subset of muscles and the motoneurons that innervate them in Drosophila. Cell 70:553-567.

Pollard TD, Cooper JA (1984) Quantitative analysis of the effect of Acanthamoeba profilin on actin filament nucleation and elongation. Biochemistry 23:6631-6641.

Pons F, Augier N, Heilig R, Leger J, Mornet D, Leger JJ (1990) Isolated dystrophin molecules as seen by electron microscopy. Proc Natl Acad Sci USA 87:7851-7855.

Prokop A, Uhler J, Roote J, Bate M (1998) The kakapo mutation affects terminal arborization and central dendritic sprouting of Drosophila motorneurons. J Cell Biol 143:1283-1294.

Prout M, Damania Z, Soong J, Fristrom D, Fristrom JW (1997) Autosomal mutations affecting adhesion between wing surfaces in Drosophila melanogaster. Genetics 146:275-285.

Robertson HM, Preston CR, Phillis RW, Johnson-Schlitz DM, Benz WK,
Engels WR (1988) A stable genomic source of P element transposase in Drosophila melanogaster. Genetics 118:461-470.

Ruhrberg C, Watt FM (1997) The plakin family: versatile organizers of cytoskeletal architecture. Curr Opin Genet Dev 7:392-397.

Schneider C, King RM, Philipson L (1988) Genes specifically expressed at growth arrest of mammalian cells. Cell 54:787-793.

Seki N, Ohira M, Nagase T, Ishikawa K, Miyajima N, Nakajima D, Nomura N, Ohara O (1997) Characterization of cDNA clones in sizefractionated cDNA libraries from human brain. DNA Res 4:345-349.

Sink H, Whitington PM (1991) Location and connectivity of abdominal motoneurons in the embryo and larva of Drosophila melanogaster. J Neurobiol 22:298-311.

Speicher DW, Marchesi VT (1984) Erythrocyte spectrin is comprised of many homologous triple helical segments. Nature 311:177-180.

Strumpf D, Volk T (1998) Kakapo, a novel cytoskeletal-associated protein is essential for the restricted localization of the neuregulin-like factor, vein, at the muscle-tendon junction site. J Cell Biol 143:1259-1270.

Tautz D, Pfeifle C (1989) A non-radioactive in situ hybridization method for the localization of specific RNAs in Drosophila embryos reveals translational control of the segmentation gene hunchback. Chromosoma 98:81-85.

Tessier-Lavigne M, Goodman CS (1996) The molecular biology of axon guidance. Science 274:1123-1133.

Togel M, Wiche G, Propst F (1998) Novel features of the light chain of microtubule-associated protein MAP1B: microtubule stabilization, self interaction, actin filament binding, and regulation by the heavy chain. J Cell Biol 143:695-707.

Torok T, Tick G, Alvarado M, Kiss I (1993) P-lacW insertional mutagenesis on the second chromosome of Drosophila melanogaster: isolation of lethals with different overgrowth phenotypes. Genetics 135:71-80.

Van Vactor DV, Sink H, Fambrough D, Tsoo R, Goodman CS (1993) Genes that control neuromuscular specificity in Drosophila. Cell 73:1137-1153.

Walsh EP, Brown NH (1998) A screen to identify Drosophila genes required for integrin-mediated adhesion. Genetics 150:791-805.

Welch MD, Mallavarapu A, Rosenblatt J, Mitchison TJ (1997) Actin dynamics in vivo. Curr Opin Cell Biol 9:54-61.

Wills Z, Marr L, Zinn K, Goodman CS, Van Vactor D (1999) Profilin and the Abl tyrosine kinase are required for motor axon outgrowth in the Drosophila embryo. Neuron 22:291-299.

Yamada KM, Wessells NK (1973) Cytochalasin B: effects on membrane ruffling, growth cone and microspike activity, and microfilament structure not due to altered glucose transport. Dev Biol 31:413-420.

Yang Y, Bauer C, Strasser G, Wollman R, Julien JP, Fuchs E (1999) Integrators of the cytoskeleton that stabilize microtubules. Cell 98:229-238.

Yang Y, Dowling J, Yu QC, Kouklis P, Cleveland DW, Fuchs E (1996) An essential cytoskeletal linker protein connecting actin microfilaments to intermediate filaments. Cell 86:655-665. 